\section{Sex dependent transmission of Beckwith-Wiedemann syndrome associated with a reciprocal translocation $\mathrm{t}(9 ; 11)(\mathrm{p} 11.2 ; \mathrm{p} 15.5)$}

\author{
Niels Tommerup, Carsten A Brandt, Søren Pedersen, Lars Bolund, Jens Kamper
}

Beckwith-Wiedemann syndrome (BWS) is a generalised overgrowth disorder characterised by large size at birth, neonatal hyperinsulinaemia and hypoglycaemia, macroglossia, umbilical abnormalities, visceromegaly, hemihypertrophy, and a highly increased risk of Wilms's tumour, adrenocortical carcinoma, and other malignancies. Although sporadic in many cases, the segregation in familial cases suggests autosomal dominant inheritance, with incomplete penetrance ${ }^{1}$ or variable expressivity. ${ }^{23}$ In many families only female carriers have affected offspring. ${ }^{45}$ This apparent sex dependent transmission has recently been explained by the demonstration of uniparental paternal disomy in association with sporadic cases of BWS, suggesting that genomic imprinting is involved. ${ }^{6}$

The cytogenetic abnormalities which have been found in association with BWS include two cases with interstitial deletion of the proximal part of $11 \mathrm{p},{ }^{78}$ several cases with duplication of the distal part of $11 \mathrm{p}$, either as de novo rearrangements or as a result of familial
The Danish Centre for Human Genome Research, The John $F$ Kennedy Institute, G1 Landevej 7, DK-2600 Glostrup, Denmark, and Department of Medical Genetics, Ullevaal University Hospital, Oslo, Norway.

$\mathrm{N}$ Tommerup

Institute of Human Genetics, University of Aarhus, Denmark.

C A Brandt

$S$ Pedersen

$\mathrm{L}$ Bolund

Department of Paediatrics, Odense Sygehus, Denmark. J Kamper

Correspondence to Dr Tommerup.

Received 30 April 1993 Accepted 7 June 1993.

\section{forms of familial BWS.}

(f Med Genet 1993;30:958-61)

Figure 1 Facial appearance of the proband at the age of $6 \frac{1}{2}$ years. 


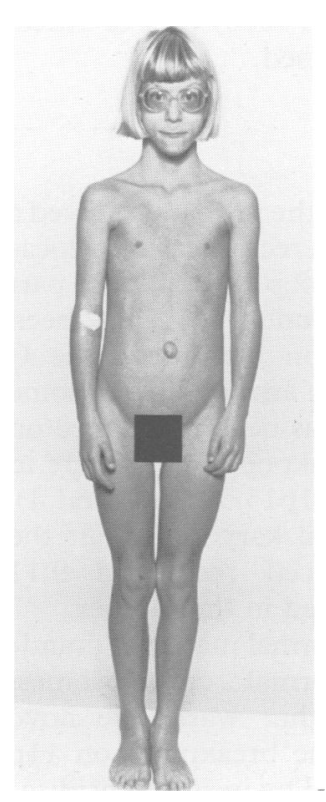

Figure 2 Front view showing bilateral femoral hypertrophy.

translocations/inversions, ${ }^{9-16}$ and apparently balanced chromosomal rearrangements associated with BWS (five reciprocal translocations, one inversion). ${ }^{1617}$

The involvement of genomic imprinting in BWS is also supported by the parental origin of the different types of associated chromosomal rearrangements. All cases analysed with duplications of $11 \mathrm{p}$ with a known parental origin have been paternally derived, ${ }^{9-16}$ and all the balanced rearrangements have been of maternal origin. ${ }^{1617}$ Furthermore, all the mothers who carried the same balanced translocations/inversions as their affected offspring have been phenotypically normal. In the context of genomic imprinting this could be explained if these maternal rearrangements were of paternal origin.

We show here the paternal origin of a de novo reciprocal translocation, $\mathrm{t}(9 ; 11)(\mathrm{p} 11 ; \mathrm{p} 15.5)$, associated with BWS in a subsequent generation.

\section{Materials and methods CASE REPORT}

The proband was the first child of a 29 year old healthy woman who had had a previous spontaneous abortion in the 10th gestational week. Paternal age was 31 years. She was delivered by caesarian at 30 weeks because of preeclampsia. Birth weight was $1233 \mathrm{~g}$ and length $40 \mathrm{~cm}$. Apgar scores were 2/1, 5/5,7/10, and $9 /$ 20 . Neonatally she developed hypoglycaemia, which was treated adequately, and respiratory

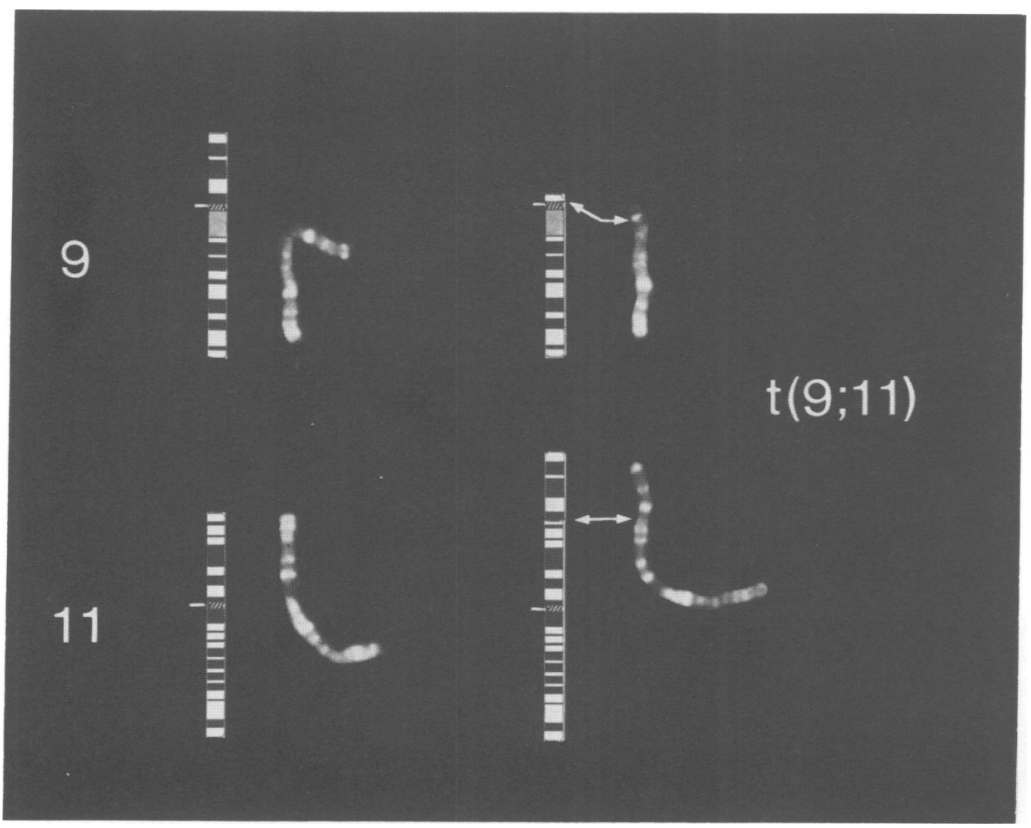

Figure 3 High resolution RBA banding of chromosomes 9 and 11. Arrows indicate the breakpoints on the two derivative translocation chromosomes.

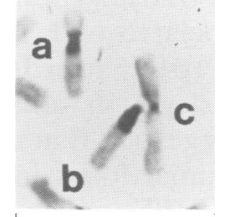

Figure 4 b banding of (a) normal chromosome 9 , (b) derivative 9 , and (c) derivative 11. distress syndrome. At the age of 2 months she was readmitted to hospital with failure to thrive and sucking difficulties and macroglossia was observed. One month later an umbilical hernia was diagnosed.

At the age of $5 \frac{1}{2}$ years her height was $126 \mathrm{~cm}$ (+3 SD) and her weight $23 \mathrm{~kg}$ (+1 SD). Slight facial dysmorphism included reduced bitemporal diameter, frontal bossing, high vaulted palate with paresis of the soft palate, and macroglossia. There were bilateral ear creases/grooves and ear pits on the right side (fig 1). A $5 \mathrm{~cm}$ umbilical hernia was observed. Her right leg was approximately $1 \mathrm{~cm}$ longer than the left, and she had a lumbar scoliosis convex to the left. There was bilateral hypertrophy of the femoral muscles (fig 2). Mentally she was only slightly retarded. There was no evidence of visceromegaly. She is now followed up every six months by abdominal ultrasound and urinary 17-ketosteroids.

Clinical examination of the mother and father shows no signs of BWS.

\section{CYTOGENETICS}

Routine $\mathrm{Q}$ banding, $\mathrm{C}$ banding, and high resolution RBA banding of the proband, both parents, and the maternal grandparents was performed essentially as described previously..$^{18}$ For staining of the heterochromatic region on chromosome 9 , the methyl green/ DAPI method ${ }^{19}$ was applied.

\section{PCR ANALYSIS OF FLOW SORTED}

\section{TRANSLOCATION CHROMOSOMES}

Flow analysis and sorting of the derivative translocation chromosomes and of the normal chromosome 11 from a lymphoblastoid cell line established from the mother was performed on a FACStar Plus (Beckton Dickinson) essentially as described previously. ${ }^{20}$ Each PCR analysis involving a specific primer set and chromosome fraction was performed a minimum of four times on 200 sorted template chromosomes. After analysis of genomic DNA from the family, primer sets of two informative chromosome 11 loci were chosen for PCR analysis of flow sorted chromosomes: D11S35 located at 11q22 (ACAATTGGATTACTACTAGC and TGTATTTGTATCGATTAACC) and D11S436 located at 11p11.22p12 (CTCAATCATAGCAGGGGAC and CACACCTGGCAATTTGCAA). The PCR conditions $\left(94^{\circ} \mathrm{C}\right.$, one minute; $55^{\circ} \mathrm{C}$, one minute; $72^{\circ} \mathrm{C}$, one minute) for 30 cycles run on

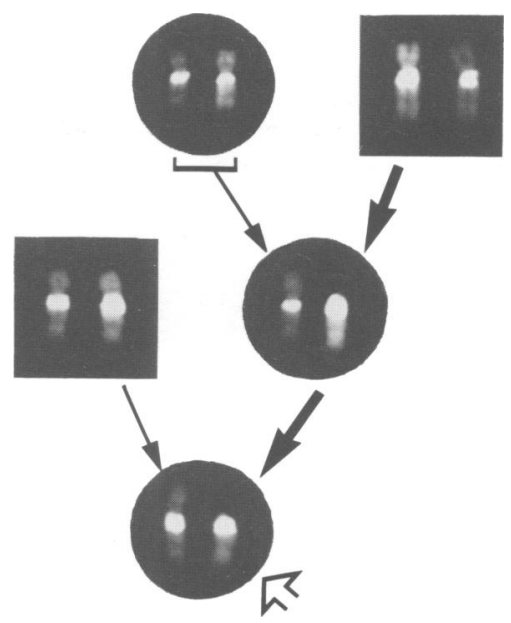

Figure 5 Methyl green/DAPI staining of chromosome 9 and derivative 9 in the proband (open arrow), the parents, and the maternal grandparents. Large arrows indicate the segregation of the large heterochromatic block from the maternal grandfather. 


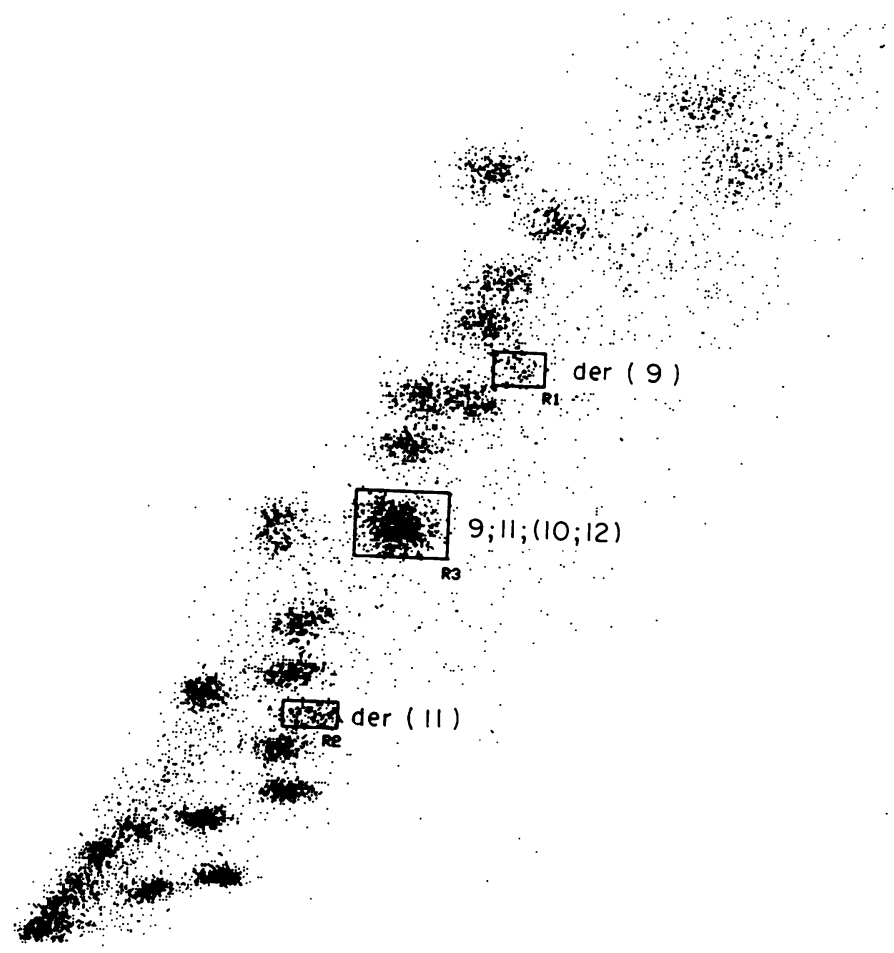

Figure 6 Flow karyotype of the maternal translocation carrier. The sorted fractions are boxed. a Perkin Elmer GeneAmp 9600) were identical for the two primer sets used.

\section{Results}

Chromosome analysis of the proband showed a female karyotype with a reciprocal translocation, 46,XX,t $(9 ; 11)(\mathrm{p} 11.2 ; \mathrm{p} 15.5)$. Thus, part of the most distal subband $11 \mathrm{p} 15.5$ has been translocated to a position just above the $\mathrm{C}$ band region on the short arm of chromosome 9 , and almost all of $9 p$ has been positioned on top of $11 \mathrm{p}$, with the breakpoint somewhere in the middle of subband $11 \mathrm{p} 15.5$ (figs 3 and 4). The father had a normal karyotype, but the same apparently balanced reciprocal 9;11 translocation was observed in the mother.

The phenotypically normal maternal grandparents both had normal chromosomes, indicating that the mother was a de novo translocation carrier. The breakpoint on $11 \mathrm{p}$ has recently been mapped by in situ hybridisation to be proximal to the insulin and insulin growth factor 2 (IGF2) locus, and distal to D11S12 (ref 16, cases 7 and 7a).

Methyl green/DAPI staining showed the presence of a large block of MG/DAPI positive heterochromatin on the long arm of the derivative translocation chromosome 9. This large block could be traced back to the maternal grandfather of the proband (fig 5).

The derivative translocation chromosomes could be clearly separated and sorted from each other and from the cluster of $C$ group chromosomes containing the normal chromosome 11 (fig 6). At both loci tested, the allele corresponding to the derivative chromosome 11 originated from the father (fig 7), indicating a paternal origin of the de novo translocation in the mother of the affected child.

\section{Discussion}

A likely candidate locus for BWS is insulin growth factor 2 (IGF2). In previous reports only the paternal allele of IGF2 was transcribed in most tissues in the mouse, ${ }^{21}$ duplication of the chromosomal segment containing the paternal IGF2 allele resulted in abnormal large mice, ${ }^{22}$ and maternal transmission of a defective IGF2 locus resulted in small mice. ${ }^{23}$ Along with this it has been suggested that an increased dosage of paternally derived IGF2 alleles, by duplication or by paternal disomy, may be involved in BWS. ${ }^{24}$

However, a preferential loss of heterozygosity of maternal $11 \mathrm{p} 15$ alleles in BWS associated tumours also supports the involvement of a maternally imprinted recessive tumour suppressor locus. ${ }^{25}$ Two clusters of breakpoints associated with the balanced translocation and inversion chromosomes associated with BWS have been identified, one at $11 \mathrm{p} 15.5$ near IGF2 as found in the present translocation, and one at p15.4. ${ }^{16}$ This led to the suggestion that there may be an additional, proximal locus in the 11 p15.4 region involved in BWS, which may be maternally imprinted and which may regulate (suppress) a growth promoting locus in the region. ${ }^{16}$ The observation of loss of heterozy-
Figure 7 Illustration of paternal origin of $t(9 ; 11)$ by $P C R$ analysis of sorted chromosomes. The lanes below the pedigrees show the PCR pattern of genomic DNA. Arrowheads indicate the paternal alleles. 
gosity within the $11 \mathrm{p} 15.4-15.5$ region in BWS associated tumours supports that lack of function also may be a mutational mechanism involved in BWS. If so, deletions involving the distal part of $11 \mathrm{p} 15$ would also be expected to occur in BWS. However, cytogenetically visible deletions involving the distal part of 11 p15 seem to be incompatible with fetal survival. ${ }^{26}$ In the absence of deletions, the types of chromosome rearrangements which will be compatible with loss of function, without gross deletion, would be balanced translocations and inversions.

The large majority ( $85 \%)$ of cases with BWS are sporadic, ${ }^{1}$ and only a small fraction is associated with a visible chromosomal aberration. ${ }^{151617}$ The present study supports that the sex dependent transmission pattern seen in the non-cytogenetic forms of BWS also applies to the cases associated with balanced chromosome mutations. Since de novo structural chromosome rearrangements are of predominantly paternal origin, ${ }^{27} 28$ it would be expected that the mode of transmission of BWS associated with such rearrangements will either follow a pattern with unaffected mothers who are de novo carriers, or a transmission pattern like father-de novo carrier father-carrier motheraffected carrier child. The latter mode of transmission might be suspected in a family with BWS associated with a pericentric inversion of chromosome $11 .^{16}$

This study was supported by The Danish Cancer Society, The Norwegian Cancer Society, and The Danish Biotechnological Research and Developmental Programme 199195. Lymphoblastoid cell lines from the two translocation carriers (1812-89L/1813-89L) are available upon request.

1 Pettenati MJ, Haines JL, Higgins RR, Wappner RS, Palmer CG, Weaver DD. Wiedemann-Beckwith syndrome: presentation of clinical and cytogenetic data on 22 new cases and review of the literature. Hum Gene

2 Best LG, Hoekstra RE. Wiedemann-Beckwith syndrome: autosomal-dominant inheritance in a family. Am $\mathcal{J}$ Med Genet 1981;9:291-9.

3 Niikawa N, Ishikiriyama S, Takahashi S, et al. The Wiedemann-Beckwith syndrome: pedigree studies on five families with evidence for autosomal dominant inheritance with variable expressivity. Am $\mathcal{F}$ Med Genet 1986;24:4155.

4 Lubinsky M, Herrmann J, Kosseff AL, Opitz JM. Autosomal-dominant sex-dependent transmission of the Wiedemann-Beckwith syndrome. Lancet 1974;i:932.

5 Aleck KA, Hadro TA. Dominant inheritance of Wiedemann-Beckwith syndrome: further evidence for transmission of unstable premutation through carrier women. $\mathrm{Am}$ f Med Genet 1989;33:155-60.
6 Henry I, Bonaïti-Pellié C, Junien C. Uniparental paternal disomy in a genetic cancer-predisposing syndrome. Nature 1991;351:665-7.

7 Schmutz SM. Deletion of chromosome 11(p11p13) in a patient with Beckwith-Wiedemann syndrome. Clin Genet 1986;30:154-6.

8 Haas OA, Zoubek A, Grumayer E, Gadner H. Constitutional interstitial deletion of $11 \mathrm{p} 11$ and pericentric inversion of chromosome 9 in a patient with WiedemannBeckwith syndrome and hepatoblastoma. Cancer Genet Cytogenet 1986;23:95-104.

9 Waziri M, Patil SR, Hanson JW, Bartley JA. Abnormality of chromosome 11 in patients with features of Beckwith Wiedemann syndrome. F Pediatr 1983;102:873-6.

10 Turleau C, de Grouchy J, Chavin-Colin F, Martelli H, Voyer M, Charlas R. Trisomy $11 \mathrm{p} 15$ and BeckwithWiedemann syndrome. A report of two cases. Hum Gene 1984;67:219-21.

11 Journel H, Lucas J, Allaire C, et al. Trisomy 11p15 and Beckwith-Wiedemann syndrome. Ann Genet (Paris) 1985;28:97-101.

12 Okano $\mathrm{Y}$, Osasa $\mathrm{Y}$, Yamamoto $\mathrm{H}$, Hase $\mathrm{Y}$, Tsuruhara $\mathrm{T}$, Fujita H. An infant with Beckwith-Wiedemann syndrome and chromosomal duplication 11p13-pter: correlation of symptoms between 11p trisomy and Beckwith-Wiedesymptoms between 11p trisomy and Beckwith-Wied
mann syndrome. fpn f Hum Genet 1986;31:365-72.

mann syndrome. Fpn f Hum Genet 1986;31:365-72.
13 Wales JKH, Walker V, Moore IE, Clayton PT. Bronze baby syndrome, biliary hypoplasia, incomplete Beckwith Wiedemann syndrome and partial trisomy 11. Eur $f$ Wiedemann syndrome
Pediatr 1986;145:141-3.

14 Brown KW, Williams JC, Maitland NJ, Mott MG. Genomic imprinting and the Beckwith-Wiedemann syndrome Am f Hum Genet 1990;46:1000-1.

15 Tonoki H, Narahara N, Marsumoto J, Niikawa N. Regional mapping of the parathyroid hormone gene (PTH) by cytogenetic and molecular studies. Cytogenet Cell Genet 1991;56:103-4.

16 Mannens M, Hoovers JMN, Redeker B, et al. Characterization of regions on human chromosome $11 \mathrm{p}$ involved in the development of Wilms' tumour associated congenital diseases. A model to study genomic imprinting in man. Eur $\mathcal{F}$ Hum Genet (in press).

17 Pueschel SM, Padre-Mendoza T. Chromosome 11 and Beckwith-Wiedemann syndrome. $\mathcal{f}$ Pediatr 1984;104: 484-5.

18 Andersen LB, Tommerup M, Koch J. Formation of a minichromosome by excision of the proximal region of $17 \mathrm{q}$ in a patient with von Recklinghausen neurofibromatosis. Cytogenet Cell Genet 1990;53:206-10.

19 Donlon TA, Magenis RE. Methyl green is a substitute for distamycin $A$ in the formation of distamycin A/DAPI Cbands. Hum Genet 1983;65:144-6.

20 Tommerup N, Schempp W, Meinecke P, et al. Assignment of an autosomal sex reversal locus (SRA1) and campomelic dysplasia (CMPD1) to 17q24.3-q25.1. Nature Genet 1993;4:170-4

21 DeChiara TM, Robertson EJ, Efstratiadis A. Parental imprinting of the mouse insulin-like growth factor II gene. Cell 1991;64:849-59.

22 Ferguson-Smith AC, Cattanach BM, Barton SC, Beechey $\mathrm{CV}$, Surani MA. Embryological and molecular investigation of parental imprinting on mouse chromosome 7 . tion of parental imprinting

23 DeChiara TM, Efstratiadis A, Robertson EJ. A growthdeficiency phenotype in heterozygous mice carrying an insulin-like growth factor II gene disrupted by targeting. Nature 1990;345:78-80.

24 Moore T, Haig D. Genomic imprinting in mammalian development: a parental tug of war. Trends Genet 1991;7:45-9.

25 Mannens M, Devilee P, Bliek J, et al. Loss of heterozygosity in Wilms' tumours, studied for 6 putative tumour-suppressor regions, is limited to chromosome 11. Cancer Res 1992;50:3279-83.

26 Tommerup N. Mendelian cytogenetics. Chromosome rearrangements associated with mendelian disorders. $\mathcal{F} \mathrm{Med}$ Genet 1993;30:713-27.

27 Chamberlin J, Magenis RE. Parental origin of de novo chromosome rearrangements. Hum Genet 1980;53:343-7.

28 Chandley AC. On the parental origin of de novo mutation in man. f Med Genet 1991;28:217-23. 